\title{
CLIMATE CHANGES AND LANDSCAPE RESPONSES OF CHINA DURING THE PAST 40 YEARS (1979-2018) UNDER KÖPPEN-GEIGER CLIMATE CLASSIFICATION
}

\author{
Y. Feng ${ }^{1}, \mathrm{~S} . \mathrm{Du}^{1, *}$ \\ ${ }^{1}$ Peking University, Beijing, China - (fyn, shdu)@pku.edu.cn
}

KEY WORDS: Climate Change, Landscape Responses, Köppen-Geiger Climate Classification, China

\begin{abstract}
:
Under the background of global warming, China with diverse climate types is experiencing dramatic climate change. In this study, we produced a series of climate type map of China at $0.1^{\circ}$ resolution from 1979 to 2018 using Köppen-Geiger climate classification, which provided continuous fine-scale decadal climate classification data for climate researches in China. Based on these climate maps, we divided China into four main climate zones: arid climate zone located on the north of Tibetan Plateau and west of Inner Mongolian Plateau, temperate climate zones in southern China, cold climate zone occupied most of Northeast Plain and North China Plain, and polar climate zone on Tibetan Plateau. The distribution of main climate classes in China have not changed significantly over 40 years, while the climate change mainly occurs at the levels of climate type and subtype changes. The frequency of climate changes shows the climate sensitivity of the region, and we identified the transition areas of climate zones with a high sensitivity to climate change. The change of climate types shows an obvious trend of rising temperature in all climate zones of China and increasing precipitation in most climate zones of China (the cold climate zone shows no significant dry or wet change). Overall, the climate in China is generally getting warmer and wetter in the past 40 years. Furthermore, we analysed the landscape responses on climate change with land cover data, e.g. the vegetation type variations in southern China and the snow cover fluctuations on Tibetan Plateau.
\end{abstract}

\section{INTRODUCTION}

China is located at the east of Asia and west of the Pacific. It covers 9.6 million $\mathrm{km}^{2}$ area with over $18000 \mathrm{~km}$ mainland coastline, including a large area of mountains and plateaus. China ranges from $70^{\circ} \mathrm{E}$ to $140^{\circ} \mathrm{E}$ and from $15^{\circ} \mathrm{N}$ to $55^{\circ} \mathrm{N}$, spanning tropical, subtropical, warm temperate, temperate and cold temperate zones. The vast land forms a great variety of climates.

Climate variability is not only reflected in spatial differentiation. It also keeps changing over time. Evidence shows that the global climate is changing rapidly these days. Recent climate changes have had widespread impacts on human and natural systems. It exposes people, societies, economic sectors and ecosystems to risk (IPCC, 2014). Yet climate change in China is even more dramatic than global climate change. Wang and Gong (2000) pointed out that the rate of warming $\left(0.3^{\circ} \mathrm{C} / 10 \mathrm{a}\right)$ over China has been considerably greater than the global warming of $0.19^{\circ} \mathrm{C} / 10 \mathrm{a}$ in the last two decades of the $20^{\text {th }}$ century. Therefore, the study of the climate change in China is of great significance to whether mitigate the climate change or adapt to it.

Köppen classification (Köppen, 1931) is a widely accepted system of climate classification. It uses natural vegetation as an expression of climate, takes monthly average air temperature and precipitation as the classification indicators to characterize temperature, precipitation and seasonality. The schemes set strict criteria to recognize the world climate as five main climate classes and 13 climate type. Although there are some criticisms of static division of climate classes (Triantafyllou, \& Tsonis, 1994), the rigid standards facilitate quick and easy access to climate classification of clear boundaries. These advantages make it a broad applied value, especially to detect recent climate changes in global, regional and country scales (Baker et al., 2010; Fraedrich et al., 2001; Wang, \& Overland, 2005; Zhu, \& Li, 2015). Thus, we intend to use Köppen classification to study the climate change in China.

Climate data are mostly based on either station measurements or gridded datasets. Station measurements are accurate and reliable, but the data acquisition is limited by the distribution of meteorological stations and the valid observation period. In China, especially on the Tibetan plateau, there is quite sparse station density on the vast plateau and mountainous area. It cannot provide sufficient valid observation data. Therefore, gridded datasets are more commonly used in large-scale climate studies, for example, Climate Research Unit (CRU) gridded data at a $2.5^{\circ}$ resolution (Kalvova et al., 2003) and $0.5^{\circ}$ resolution (Fraedrich et al., 2001), China monthly surface air temperature and precipitation $0.5^{\circ} \times 0.5^{\circ}$ gridded dataset $(\mathrm{Zhu}$, $\& \mathrm{Li}, 2015)$, etc. However, these resolutions are a little bit coarse and any sub-grid resolution climate variability will be ignored. Thus, a finer scale study on climate classification is needed. Then Peel et al (2007) interpolated the whole period of station record onto a $0.1^{\circ} \times 0.1^{\circ}$ grid and made one highresolution global map of Köppen climate classification to reflect long-term world climate. This updated climate map is widely accepted in the field of climate change. But unfortunately, only one phase of climate classification is not enough for time series analysis to detect the climate change.

In this study, we would like to select a long-term highresolution meteorological dataset to produce a series of finerscale climate classification map for climate dynamic studies. Furthermore, we will discuss the land cover changes in different climate zones to disclose the landscape responses on climate change.

\footnotetext{
* Corresponding author
} 


\begin{tabular}{|c|c|c|c|c|}
\hline Class & Type & Subtype & Description & Criteria* \\
\hline \multirow[t]{4}{*}{ A } & & & Tropical & $\mathrm{T}_{\text {cold }} \geq 18$ \\
\hline & $\mathrm{f}$ & & -Rainforest & $P_{\text {dry }} \geq 60$ \\
\hline & $\mathrm{m}$ & & -Monsoon & Not (Af) \& $P_{\text {dry }} \geq 100-M A P / 25$ \\
\hline & $\mathrm{w}$ & & -Savannah & Not (Af) \& $\mathrm{P}_{\text {dry }}<100-\mathrm{MAP} / 25$ \\
\hline \multirow[t]{5}{*}{ B } & & & Arid & MAP $<10 \times \mathrm{P}_{\text {threshold }}$ \\
\hline & $\mathrm{W}$ & & -Desert & MAP $<5 \times$ Pthreshold $_{1}$ \\
\hline & S & & -Steppe & MAP $\geq 5 \times \mathrm{P}_{\text {threshold }}$ \\
\hline & & $\mathrm{h}$ & - Hot & $\mathrm{MAT} \geq 18$ \\
\hline & & $\mathrm{k}$ & -Cold & $\mathrm{MAT}<18$ \\
\hline \multirow[t]{7}{*}{$\mathrm{C}$} & & & Temperate & $\mathrm{T}_{\text {hot }}>10 \& 0<\mathrm{T}_{\text {cold }}<18$ \\
\hline & $\mathrm{s}$ & & -Dry Summer & $\mathrm{P}_{\text {sdry }}<40 \& \mathrm{P}_{\text {sdry }}<\mathrm{P}_{\mathrm{wwet}} / 3$ \\
\hline & $\mathrm{w}$ & & -Dry Winter & $\mathrm{P}_{\mathrm{wdry}}<\mathrm{P}_{\text {swet }} / 10$ \\
\hline & $f$ & & -Without dry season & $\operatorname{Not}(\mathrm{Cs})$ or $(\mathrm{Cw})$ \\
\hline & & $\mathrm{a}$ & -Hot Summer & $\mathrm{T}_{\text {hot }} \geq 22$ \\
\hline & & $\mathrm{b}$ & -Warm Summer & Not (a) \& $T_{\operatorname{mon} 10} \geq 4$ \\
\hline & & $\mathrm{c}$ & -Cold Summer & $\operatorname{Not}(\mathrm{a}$ or $\mathrm{b}) \& 1 \leq \mathrm{T}_{\operatorname{mon} 10}<4$ \\
\hline \multirow[t]{8}{*}{$\mathrm{D}$} & & & Cold & $\mathrm{T}_{\text {hot }}>10 \& \mathrm{~T}_{\text {cold }} \leq 0$ \\
\hline & $\mathrm{s}$ & & -Dry Summer & $\mathrm{P}_{\text {sdry }}<40 \& \mathrm{P}_{\text {sdry }}<\mathrm{P}_{\text {wwet }} / 3$ \\
\hline & $\mathrm{w}$ & & -Dry Winter & $\mathrm{P}_{\mathrm{wdry}}<\mathrm{P}_{\text {swet }} / 10$ \\
\hline & $\mathrm{f}$ & & -Without dry season & Not (Ds) or (Dw) \\
\hline & & $\mathrm{a}$ & -Hot Summer & $\mathrm{T}_{\text {hot }} \geq 22$ \\
\hline & & $\mathrm{b}$ & -Warm Summer & Not (a) \& $T_{m o n 10} \geq 4$ \\
\hline & & $\mathrm{c}$ & -Cold Summer & $\operatorname{Not}(a, b$ or $d)$ \\
\hline & & $\mathrm{d}$ & -Very cold Winter & Not $(a$ or $b) \& T_{\text {cold }}<-38$ \\
\hline \multirow[t]{3}{*}{$\mathrm{E}$} & & & Polar & $\mathrm{T}_{\text {hot }}<10$ \\
\hline & $\mathrm{T}$ & & -Tundra & $\mathrm{T}_{\text {hot }}>0$ \\
\hline & $\mathrm{F}$ & & -Frost & $\mathrm{T}_{\mathrm{hot}} \leq 0$ \\
\hline
\end{tabular}

$* \mathrm{MAP}=$ mean annual precipitation, MAT $=$ mean annual temperature, Thot $=$ temperature of the hottest month, Tcold $=$ temperature of the coldest month, Tmon $10=$ number of months where the temperature is above 10, Pdry = precipitation of the driest month, Psdry = precipitation of the driest month in summer, Pwdry= precipitation of the driest month in winter, Pswet = precipitation of the wettest month in summer, Pwwet $=$ precipitation of the wettest month in winter, Pthreshold $=$ varies according to the following rules (if $70 \%$ of MAP occurs in winter then Pthreshold $=2 \times$ MAT, if $70 \%$ of MAP occurs in summer then Pthreshold $=2 \times$ MAT +28 , otherwise Pthreshold $=2 \times$ MAT +14 ). Summer (winter) is defined as the warmer (cooler) six-month period of ONDJFM and AMJJAS.

Table 1. Description of Köppen climate symbols and defining criteria

\section{DATA AND METHODOLOGY}

\subsection{Meteorological Dataset}

We used the China Meteorological Forcing Dataset (CMFD), a high spatial-temporal resolution gridded near-surface meteorological dataset, which was made through fusion of remote sensing products, reanalysis dataset and in-situ observation data at weather stations. Data were recorded from January 1979 to December 2018 with a temporal resolution of three hours and a spatial resolution of $0.1^{\circ}$ (Yang, \& He, 2018). We pre-processed the $2 \mathrm{~m}$ air temperature and precipitation rate data provided by CMFD and made the statistical calculation to obtain monthly average air temperature and precipitation.

\subsection{Köppen-Geiger Climate Classification}

We used the modified Köppen-Geiger climate classification (Peel, Finlayson, \& Mcmahon, 2007) to determine the distribution of climatic type. This modified classification identifies five main climate classes using letters $\mathrm{A}$ to $\mathrm{E}$, A for tropical, $\mathrm{C}$ for temperate, $\mathrm{D}$ for cold, $\mathrm{E}$ for polar and $\mathrm{B}$ for arid. First four of them are based on the thermic zones and the last one is generated from the dry condition. Then these climate classes are further subdivided by the seasonality of temperature and precipitation to 13 climate types and 31 climate subtypes (Table 1). We used the SAGA software for climate classification (Conrad et al., 2015).

\subsection{Landscape Responses}

To explore the landscape responses to climate change, we combined the land cover changes with the change of climate zones. The time series of land cover changes were derived by the MODIS Combined Terra and Aqua Land Cover Type Yearly L3 Global 0.05Deg Climate Modelling Grid (CMG) (short name: MCD12C1) (Friedl, \& Sulla-Menashe, 2015). The International Geosphere Biosphere Programme (IGBP) global vegetation classification scheme is used in this study, which identifies 17 land cover classes including 11 natural vegetation classes, 3 developed and mosaicked land classes, and 3 nonvegetated land classes.

For the polar climate zones on the Tibetan plateau, snow cover is a strong indicator of climate change (Cess, et al., 1991). MODIS/Terra Snow Cover 8-Day L3 Global 500m SIN Grid (short name: MOD10A2) reports the maximum snow cover extent during an eight-day period in $500 \mathrm{~m}$ resolution (Hall, \& Riggs., 2016). We used MOD10A2 data set to calculate the maximum snow cover in the coldest and hottest months of each year to reflect the annual snow cover changes.

To explore the landscape responses on climate change, we calculated the land cover changes on the regional scales and fitted the land cover changes with climate type changes to analyse the relationship between them and reveal the impact of climate change on the landscape. 

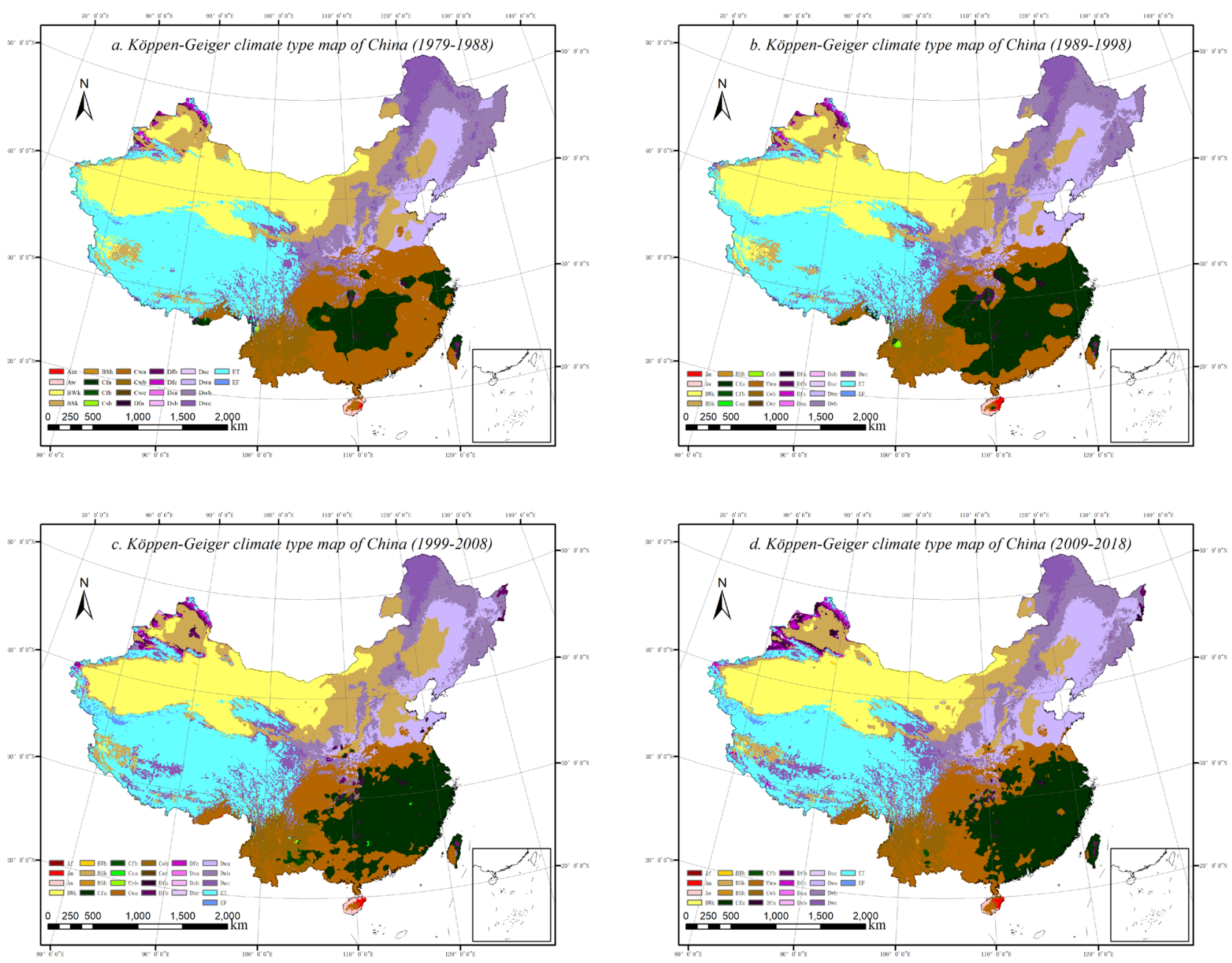

Figure 1. Decadal change of Köppen-Geiger climate type map of China in past 40 years

\section{RESULTS}

The map of Köppen-Geiger climate type for China in time series (Fig. 1) shows that all five main climate classes are present in China. The distribution of main climate classes remains stable and the dominant climate class by area is the arid B $(29.4 \%)$, followed by cold D (26.8\%), temperate C $(24.0 \%)$, polar E (19.5\%) and tropical A $(0.2 \%)$ (Table 2$)$.

The tropical (A) climate only covers a small area, mostly in Hainan Island, and it changes little in the past 40 years. Most part of China are occupied by B, C, D \& E climate classes, particularly six main climate types, desert BW, steppe BS, temperate with dry winter $\mathrm{Cw}$, temperate without dry season $\mathrm{Cf}$, cold with dry winter Dw and tundra ET.

The maps depict that China can be roughly divided into four climate zones: Tibetan Plateau (Region I) is mainly covered by the polar (E) climate; the southern China (Region II) which is located on the east of Tibetan Plateau and south of Qinling Mountain and Huaihe River is in the coverage of temperate (C) climate; the region on the north of Tibetan Plateau and west of Inner Mongolian Plateau (included) (Region III) is identified as arid (B) climate; and cold (D) climate occupies most of Northeast Plain and North China Plain on the east of Inner
Mongolian Plateau and north of Qinling Mountain and Huaihe River (Region IV) (Fig. 2).

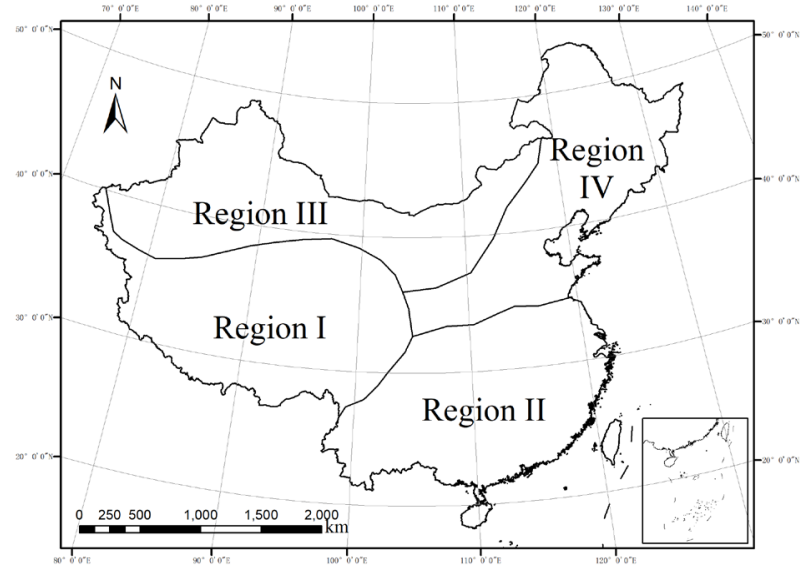

Figure 2. The main climate zones in China

Region I has a polar climate, mainly the tundra (ET) climate. But in the past 40 years, there is a reduction in ET climate by 


\begin{tabular}{|c|c|c|c|c|}
\hline \multirow{2}{*}{$\begin{array}{c}\text { Climate } \\
\text { Type }\end{array}$} & \multicolumn{4}{|c|}{ Area $\left(\times 98.60 \mathrm{~km}^{2}\right)$} \\
\hline & $\begin{array}{c}1979- \\
1988\end{array}$ & $\begin{array}{c}1989- \\
1998\end{array}$ & $\begin{array}{l}1999- \\
2008\end{array}$ & $\begin{array}{c}2009- \\
2018\end{array}$ \\
\hline A & 201 & 256 & 282 & 191 \\
\hline Af & 0 & 0 & 2 & 3 \\
\hline $\mathrm{Am}$ & 20 & 91 & 75 & 76 \\
\hline Aw & 181 & 165 & 205 & 112 \\
\hline B & 29481 & 28256 & 30599 & 26700 \\
\hline BWk & 18244 & 18246 & 16208 & 15675 \\
\hline BWh & 0 & 0 & 9 & 16 \\
\hline BSk & 11227 & 10006 & 14373 & 10990 \\
\hline $\mathrm{BSh}$ & 10 & 4 & 9 & 19 \\
\hline $\mathbf{C}$ & 23156 & 23244 & 23733 & 23770 \\
\hline $\mathrm{Cfa}$ & 5571 & 11007 & 11215 & 11203 \\
\hline $\mathrm{Cfb}$ & 297 & 292 & 292 & 149 \\
\hline $\mathrm{Cfc}$ & 0 & 0 & 0 & 0 \\
\hline Csa & 0 & 7 & 18 & 0 \\
\hline $\mathrm{Csb}$ & 17 & 35 & 13 & 0 \\
\hline $\mathrm{Csc}$ & 0 & 0 & 0 & 0 \\
\hline Cwa & 13916 & 8672 & 9047 & 9391 \\
\hline $\mathrm{Cwb}$ & 3353 & 3230 & 3141 & 3027 \\
\hline Cwc & 2 & 1 & 7 & 0 \\
\hline D & 24672 & 26458 & 24401 & 29121 \\
\hline Dfa & 70 & 118 & 230 & 469 \\
\hline $\mathrm{Dfb}$ & 400 & 557 & 961 & 851 \\
\hline Dfc & 382 & 367 & 568 & 802 \\
\hline Dfd & 0 & 0 & 0 & 0 \\
\hline Dsa & 4 & 3 & 7 & 40 \\
\hline Dsb & 12 & 1 & 27 & 21 \\
\hline Dsc & 5 & 1 & 24 & 23 \\
\hline Dsd & 0 & 0 & 0 & 0 \\
\hline Dwa & 6428 & 8445 & 7122 & 9947 \\
\hline Dwb & 11709 & 12157 & 9701 & 11117 \\
\hline Dwc & 5662 & 4809 & 5761 & 5851 \\
\hline Dwd & 0 & 0 & 0 & 0 \\
\hline $\mathbf{E}$ & 20201 & 19497 & 18696 & 17929 \\
\hline ET & 19949 & 19290 & 18270 & 17559 \\
\hline $\mathrm{EF}$ & 252 & 207 & 426 & 370 \\
\hline TOTAL & 97711 & 97711 & 97711 & 97711 \\
\hline
\end{tabular}

Table 2. Area of each climate type of China in past 40 years

$-5.7 \times 10^{4} \mathrm{~km}^{2} / 10 \mathrm{a}$, which is accompanied by an upward trend of Dwc climate (Fig. 1). The trend from polar climate to cold climate indicates that the Tibetan Plateau becomes warming these years, which is consistent with Wu et al.'s findings (2005). The statistic result also shows some climate-subtype conversion from BWk to BSk climate in the western Tibetan Plateau. These two climate types are two subtype of the cold arid climate which differ in the mean annual precipitation. Although they are both arid climates, BWk climate has even less precipitation than BSk climate does. Therefore, the change from BWk to BSk climate reflects the increasing precipitation on the Tibetan Plateau, which confirms Wu et al.'s conclusion (2015) again that the main trends of climate change on Tibetan Plateau are temperature rise and precipitation increase, and most of the areas was ascending to more humid status.

Region II is located in southern China with temperate (C) climate, mainly including temperate climate with dry winter and hot summer (Cwa), temperate climate with dry winter and warm summer $(\mathrm{Cwb})$ and temperate climate with hot summer but without any dry seasons (Cfa). Cwa climate was the main climate type in 1980 s with $57 \%$ coverage of this region (Fig. 1 (a)). But in the following 40 years, a decrease occurred in the Cwa climate while the $\mathrm{Cfa}$ climate showed a sharp upward trend (Fig. 1(b)-(d)). In the climate map of the latest decade (2009-2018), Cfa became the dominate climate type of this region with $48 \%$ coverage compared with the $36 \%$ coverage of Cwa climate (Fig. 1(d)). It indicates that more and more areas in southern China no longer have any dry seasons these days, showing a general trend from dry to rather humid condition of this region. In addition, the $\mathrm{Cwb}$ climate had a modest decrease with a trend of $-1.3 \times 10^{4} \mathrm{~km}^{2} / 10$ a from 1979 to 2018 . Figure 1 shows that the region with a reduction of $\mathrm{Cwb}$ climate is covered by Cwa climate now. In another word, there is a trend from $b$ subtype (warm summer) to $a$ subtype (hot summer). In the climate map (2009-2018), a subtype (hot summer) has occupied $86 \%$ area of Region II and shows that the southern China is keeping warming.

In Region III, cold desert (BWk) climate dominates most of the area varying with little overall trend in past 40 years. The only climate change happens at the Junggar Basin in the northwest of China. In the 1980s, Junggar Basin was under the coverage of BWk climate (Fig. 1(a)) which was gradually replaced by the cold steppe (BSk) climate in the next few decades (Fig. 1(b)(d)). At the same period, the cold climate (Df and Dw) is also increasing slightly in this area. Until now, Junggar Basin is basically occupied by BSk climate (Fig. 1(d)). Although it is still under the arid climate, it has more precipitation now than in the 1980 s.

As for Region IV, there are three subtypes $(a, b, c)$ of cold climate with dry winter (Dw) and cold steppe (BSk) climate (Fig. 1). The BSk climate has a relatively constant coverage (15\%) from 1979 to 2018 . But in the areas covered by Dw climate, the increase in the coverage of Dwa climate was accompanied by the deceases in the coverage of both the Dwb and Dwc climate, which indicated the warming trend of the whole region.

According to the decadal change of Köppen-Geiger climate type map of China, although the distribution of main climate classes in China have not changed significantly in the past 40 years, the climate types in each climate zone have been changing among each other. There is an obvious trend of rising temperature in all climate zones of China and increasing precipitation in most climate zones of China (Region III shows no significant dry or wet change). To sum up, the climate in China is generally getting warmer and wetter in the past 40 years.

\section{DISCUSSION}

\subsection{Climate change and climate-sensitive regions in China}

We compared four climate maps and calculated the frequency of the climate change over 40 years. $65 \%$ of the area did not have any changes on the climate types and we called it a stable climate zone. $22 \%$ of the area only change the climate type once. $11 \%$ of the area has twice climate type changes. While the climate types on $2 \%$ of the area kept changing in the past 40 years and we believed that it is sensitive to the climate change (Fig. 3).

In Figure 3, we can intuitively see the regions with frequent changes in the climate types, that is, climate-sensitive regions. Except the western Tibetan Plateau, Junggar Basin and the 
humid regions in southern China that we have mentioned in Section 3, the climate-sensitive regions are mainly concentrated around the Hu Line (Heihe-Tengchong) and Qinling MountainHuaihe River Line. Hu Line is the boundary between east and west of China, while Qinling Mountain-Huaihe River Line divides China into northern China and southern China. Both of them are located on the transition areas of climate zones and show the high sensitivity to climate change. We need to pay more attention to this region in order to make a timely targeted response to climate change.

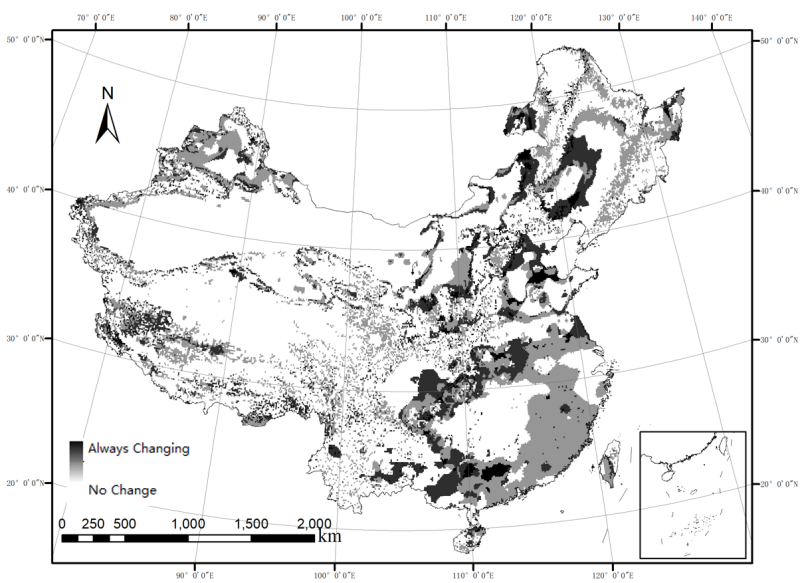

Figure 3. Climate type change in China (1979-2018)

\subsection{The climate shift at Junggar Basin from desert climate to steppe climate}

As a sensitive desert ecosystem, Junggar Basin is highly susceptible to environmental impacts. Its local climate change is affected by the local atmospheric circulation under the background of global warming (Feng et al., 2006). Combined with the unique location in the transitional region between the east Asian monsoon climate and the Mediterranean climate, it becomes an indicator of global climate change (Wei et al., 2003). According to the climate maps, the cold desert (BWk) climate at Junggar Basin was gradually replaced by the cold steppe (BSk) climate in the past 40 years with the rising temperature and increasing precipitation. However, based on the land cover classification results provided by MCD12C1 product, the land cover of Junggar Basin has not changed significantly and is still dominates by barrens. That is means the Junggar Basin is still suffering desertification. Despite the rising trend in precipitation, the surface evaporation also grows with the increase of the air temperature. Therefore, the arid climate research like Junggar Basin should integrate more meteorological factor in order to protect the ecological environment of arid areas in the context of global climate change.

4.3 The expansion of temperate climate without dry seasons in southern China and the following vegetation responses

The southern China is dominated by the temperte cliamte and has gradually converted from Cwa climate to Cfa climate in the past 40 years. The transition from dry winter to no dry season in whole year indicates the general wetter trend. According to the data availability of $\mathrm{MCD} 12 \mathrm{C} 1$ product, we calculated the coverage of each kind of land cover in south China from 2001 to 2018 and plotted them as Figure 4.

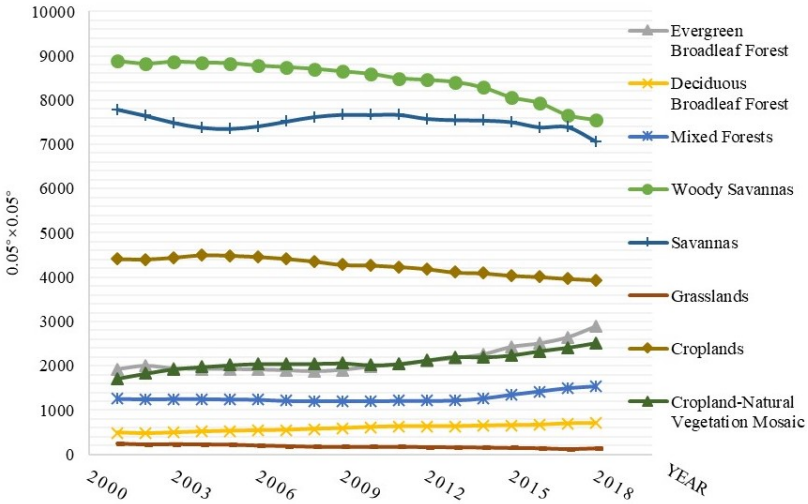

Figure 4. Vegetation Responses on Climate Change

The figure shows that there are mainly savannas and woody savannas in south China, but with the decrease trend year by year, while the area of evergreen broadleaf forest, croplandnatural vegetation mosaic and mixed forest is increasing in these years, especially the evergreen broadleaf forest with an annual growth rate of $1.15 \%$. The growth of forests is due to the warm and humid environment. The increase of forest and decrease of herbaceous and graminoids plants are clear responses to climate change of recent decades in southern China, as well as a full embodiment of earth surface modification by climate change.

\subsection{The climate change on Tibetan Plateau and the corresponding snow responses}

In the interdecadal climate change, there is a trend towards reduced coverage of ET climate on Tibetan Plateau. However, the coverage of ET climate presents a stable fluctuation in the annual climate classification from 2001 to 2018. This difference is mainly because that the smoothing of interdecadal data removed the interannual variability, which makes it reflect the long-term law better. But they both reflect the real climate change just on the different time scales.

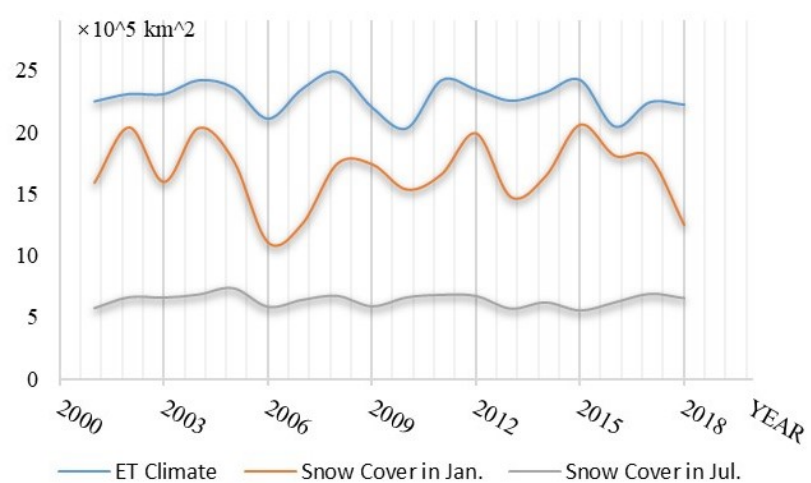

Figure 5. Snow responses to ET climate change

Combing climate change with local snow cover (Fig. 5), we found that the fluctuation of snow cover area in the coldest month of each year is consistent with the fluctuation trend of ET climate area. The variation range of snow cover area is more dramatic and slightly delayed than the ET climate changes. The snow cover change in the hottest month of each year is relatively flat, but it also shows a consistent trend with ET climate change after data standardization. Through the verification of high correlation between snow cover and ET climate change, we can use the snow cover data to reflect the 
climate change on Tibetan Plateau intuitively and make reasonable climate evaluation and prediction. Nowadays, snow cover data can be easily and quickly obtained by remote sensing, which is a good support for climate researches, particularly the areas that lack field observation data.

\section{CONCLUSIONS}

In this study, we produced a series of climate type map of China at $0.1^{\circ}$ resolution from 1979 to 2018 using KöppenGeiger climate classification, which provided continuous finescale decadal climate classification data for climate researches in China. Based on these climate maps, we divided China into four main climate zones: 1) Arid climate (B) zone, located on the north of Tibetan Plateau and west of Inner Mongolian Plateau. The main climate types are BWk and BSk. 2) Temperate climate (C) zones in southern China. The main climate types are Cfa, Cwa and Cwb. 3) Cold climate (D) zone, occupied most of Northeast Plain and North China Plain. The main climate types are Dwa, Dwb and Dwc. 4) Polar climate (E) zone on Tibetan Plateau. The main climate type is ET.

The distribution of main climate classes in China have not changed significantly over 40 years, while the climate change mainly occurs at the levels of climate type and subtype changes. Then we analysed the climate change in two aspects, how often it changed and what kind of climate type conversion happened. On the one hand, the frequency of climate change shows the climate sensitivity of the region. Thus, we identified the transition areas of climate zones with a high sensitivity to climate change. On the other hand, the change of climate types reflects an obvious trend of rising temperature in all climate zones of China and increasing precipitation in most climate zones of China (the cold climate zone shows no significant dry or wet change). Overall, the climate in China is generally getting warmer and wetter in the past 40 years.

Furthermore, we analysed the landscape responses on climate change with land cover data. In southern China, the warm and humid trend of climate change would lead to the increase of forest and decrease of herbaceous and graminoids plants. For the regions with polar climate, snow cover change has a high correction with the ET climate change, which makes it become an efficient indicator in climate researches. The situation in arid regions is more complicated. The landscape responses on climate change are unclear under the balance between the increase of precipitation and the increase of evaporation caused by the rising temperature. So more meteorological variables need to be introduced to solve this question in the future work.

\section{ACKNOWLEDGEMENTS}

This work is funded by the National Natural Science Foundation of China, grant number 41871372. The China Meteorological Forcing Dataset is provided by the National Tibetan Plateau Data Center (https://data.tpdc.ac.cn/). The MODIS Combined Terra and Aqua Land Cover Type Yearly L3 Global 0.05Deg CMG was acquired from the Level-1 and Atmosphere Archive \& Distribution System (LAADS) Distributed Active Archive Center (DAAC), located in the Goddard Space Flight Center in Greenbelt, Maryland (https://ladsweb.nascom.nasa.gov/).

\section{REFERENCES}

Baker, B., Diaz, H., Hargrove, W., \& Hoffman, F., 2010. Use of the köppen-trewartha climate classification to evaluate climatic refugia in statistically derived ecoregions for the people's republic of china. Climatic Change, 98(1-2), 113-131.

Conrad, O., Bechtel, B., Bock, M., Dietrich, H., Fischer, E., Gerlitz, L., Wehberg, J., Wichmann, V., and Böhner, J., 2015. System for Automated Geoscientific Analyses (SAGA) v. 2.1.4, Geosci. Model Dev., 8, 1991-2007, doi:10.5194/gmd-8-19912015.

Cess, R. D., Potter, G. L., Zhang, M. H., Blanchet, J. P., Chalita, S., \& Colman, R., et al., 1991. Interpretation of snow-climate feedback as produced by 17 general circulation models. Science, 253(5022), 888-892.

Fraedrich, K., Gerstengarbe, F.W., Werner, P.C., 2001. Climate shifts during the last century. Clim Change 50:405-417.

Feng, S., Huang, Y., Xu, Y., 2006. Impact of Global Warming on the Water Cycle in Xinjiang Region. Journal of Glaciology and Geocryology, 28(4), 500-505.

Friedl, M., Sulla-Menashe, D., - NASA GSFC and MODAPS SIPS - NASA., 2015. MCD12C1 MODIS Terra+Aqua Land Cover Type Yearly L3 Global 0.05Deg CMG. NASA LP DAAC. http://doi.org/10.5067/MODIS/MCD12C1.006.

Hall, D. K. and Riggs, G. A., 2016. MODIS/Terra Snow Cover 8-Day L3 Global 500m SIN Grid, Version 6. Boulder, Colorado USA. NASA National Snow and Ice Data Center Distributed Active Archive Center. doi: https://doi.org/10.5067/MODIS/MOD10A2.006.

Intergovernmental Panel on Climate Change. Climate Change 2014 Synthesis Report, 2014.

Kalvova, J., Halenka, T., Bezpalcova, K., and Nemesova, I., 2003. Köppen Climate types in observed and simulated climates, Stud. Geophys. Geod., 47, 185-202.

Köppen, W., 1931. 'Grundriss der Klimakunde', Walter de Gruyter, Berlin, 388pp.

Peel, M. C., Finlayson, B. L., Mcmahon, T.A., 2007. Updated world map of the Köppen-Geiger climate classification. Hydrology and Earth System Sciences Discussions, European Geosciences Union, 11 (5), pp.1633-1644. hal-00305098.

Triantafyllou, G.N., Tsonis, A.A., 1994. Assessing the ability of the Köppen system to delineate the general world pattern of climates. Geophys. Res. Lett. 21(25): 2809-2812.

Wang, M., Overland, J.E., 2005. Detecting arctic climate change using Köppen climate classification. Clim Change 67:43-62.

Wang, S., Gong, D., 2000. Enhancement of the warming trend in China. Geophys Res Lett 27:2581-2584.

Wei, W., He, Q., Liu, M., Gao, W., 2003. Climate Change and the Desert Environment in Junggar Basin, Xinjiang, China. Journal of Desert Research, 2, 101-105. 
Wu, S., Yin, Y., Zheng, D., Yang, Q., 2005. Climate Changes in the Tibetan Plateau during the Last Three Decades. Acta Geographica Sinica, 60(1): 3-11.

Yang, K., He, J., 2018. China meteorological forcing dataset (1979-2018). National Tibetan Plateau Data Center. doi:10.3972/westdc.002.2014.db.
Zhu, G., Li, Y., 2015. Types and changes of Chinese climate zones from 1961 to 2013 based on Köppen climate classification. Arid Land Geography, 38(6):1121-1132. 